\title{
Does mean platelet volume/lymphocyte count ratio associate with frailty in type 2 diabetes mellitus?
}

\author{
Bilgin S, Aktas G, Kahveci G, Atak Tel BM, Kurtkulagi O, Taslamacioglu Duman T
}

Abant Izzet Baysal University Hospital, Department of Internal Medicine, Bolu, Turkey. draliaktas@yahoo.com

\begin{abstract}
OBJECTIVES: Frailty is a common problem in patients with type 2 diabetes mellitus (T2DM). It is considered to be associated with inflammation. Novel markers derived from hemogram, such as neutrophil/lymphocyte ratio (NLR) and mean platelet volume/lymphocyte ratio (MPVLR), are proposed as inflammatory markers. In present study, we aimed to compare NLR and MPVLR levels of frail patients with T2DM to non-frail diabetic subjects.

METHODS: Diabetic subjects were grouped in frail and non-frail groups according to the Edmonton Frail Scale. General characteristics and laboratory data of the frail and non-frail groups were compared.

RESULTS: The MPVLR of the frail (3.9 [1.4-13.2] \%) group was significantly higher than that of the non-frail $(3.4[1.5-6.9] \%)$ group $(p=0.02)$. MPVLR was positively and significantly correlated with Edmonton Frail Scale score $(r=0.21, p=0.03)$. A MPVLR level greater than $3.41 \%$ has $71 \%$ sensitivity and $51 \%$ specifity in predicting frailty.

CONCLUSION: We suggest that elevated MPVLR could be a finding that marks frailty in diabetic subjects. Inexpensive and easy-to-assess nature of the MPVLR may be useful in predicting frailty in type 2 diabetic population (Tab. 2, Fig. 1, Ref. 32). Text in PDF www.elis.sk

KEY WORDS: mean platelet volume/lymphocyte ratio, frailty, inflammation, type 2 diabetes mellitus.
\end{abstract}

\section{Introduction}

Type 2 diabetes mellitus (T2DM) is one of the chronic diseases that are reaching the epidemic level all over the world (1). It is possible to reduce complications by reducing glycated hemoglobin (HbA1c) levels below \%7, which is the target of treatment in T2DM (2, 3). Glycemic targets may be higher for elderly patients or patients with comorbidity (4). There are several studies showing that there is a relationship between diabetic regulation and neutrophil-to-lymphocyte ratio (NLR) and mean platelet volume-to-lymphocyte ratio (MLR) (5-8). Frailty is a general name for the situation resulting from the breakdown of many systems due to the decrease in the homeostatic system and flexibility (9, 10). Edmonton Frail Scale tests vulnerability in older people. The resulting score ranges from 0 to 17 and classifies subjects as being not frail, apparently vulnerable, slightly frail, moderately frail and severely frail (11). There is a relationship between Edmonton Frail Scale, HbA1c levels and duration of diabetes (12).

In present study, we aimed to compare MPVLR and NLR levels of the frail and non-frail type 2 diabetic subjects. We also aimed to study whether these parameters predict frailty.

Abant Izzet Baysal University Hospital, Department of Internal Medicine, Bolu, Turkey

Address for correspondence: G. Aktas, MD, Abant Izzet Baysal University Hospital, Department of Internal Medicine, Golkjoy, 14280, Bolu, Turkey. Phone: +903742534656, Fax: +903742534615

\section{Methods}

Study population

After obtaining approval of the local ethics committee (approval number: 2020/167) we retrospectively analyzed data of subjects with T2DM who showed up in outpatient internal medicine clinics of our institution. Patients with active infection, chronic inflammatory disease (i.e. rheumatoid arthritis), cancer, and pregnancy were excluded from the study. Remaining subjects were grouped into two groups either as frail or non-frail according to the Edmonton Frail Scale score.

\section{Laboratory Analyses}

Age, gender, height, body weight, waist circumference, and duration of T2DM were noted. Laboratory indices, including, HbA1c, fasting plasma glucose (FPG), blood urea, creatinine, uric acid, glomerular filtration rate (GFR), c-reactive protein (CRP), serum albumin, serum lipids (triglyceride and total, HDL and LDL cholesterols), and hemogram parameters: $\mathrm{Hb}$, neutrophil count, lymphocyte count and mean platelet volume were obtained from the database and patients' files and recorded. Edmonton Frail Scale scores of all participants were recorded. Patients with an HbA1c level lower than $7 \%$ are assigned as well-controlled diabetics and the remaining subjects were assigned as poorly controlled diabetics. The presence of coronary heart disease, peripheral arterial disease, cerebrovascular disease, diabetic retinopathy, and nephropathy were also noted. The body mass index was calculated 
by dividing weight in kilograms by square of height in meters. NLR was calculated by simple division of neutrophil count by lymphocyte count. MPVLR was calculated by dividing MPV by lymphocyte count. General characteristics and laboratory data of the frail and non-frail groups were compared.

\section{Statistical analyses}

The distribution of variables in study groups was analyzed with Kolmogorov Smirnov test. Variables with normal distribution were expressed as mean \pm standard deviation and compared by independent samples t-test. Variables without normal distribution were expressed as median (min.-max.) and compared with Mann-Whitney U test. The comparison of categorical variables was conducted with chi-square test. The correlation between study variables was analyzed with Spearman's correlation analysis test. The value of MPVLR predictive of frailty in diabetics was analyzed by receiver operative characteristics (ROC) test. A p value lower than 0.05 was considered statistically significant.

\section{Results}

Study population consisted of 108 subjects; 42 were in frail and 66 in non-frail groups. Median age of the frail and non-frail groups were 65 (50-78) years and 62 (50-79) years, respectively

Tab. 1. General characteristics and laboratory data of the study population.

\begin{tabular}{lccc}
\hline & Frail group & Non-frail group & $\mathrm{p}$ \\
\hline Men (n, \%) & 15 & 36 & 0.06 \\
Women (n, \%) & 27 & 30 & \\
\hline \multicolumn{4}{c}{ Mean \pm SD } \\
\hline Weight (kg) & $80 \pm 17$ & $83 \pm 12$ & 0.25 \\
BMI (kg/m2) & $32.2 \pm 6.3$ & $30.9 \pm 5.2$ & 0.24 \\
Waist circumference (cm) & $106 \pm 13$ & $105 \pm 11$ & 0.68 \\
Hb (g/dL) & $13 \pm 1.7$ & $13.7 \pm 1.7$ & $\mathbf{0 . 0 4}$ \\
HbA1c (\%) & $8.4 \pm 2.4$ & $7.7 \pm 1.5$ & 0.06 \\
GFR (\%) & $74 \pm 16$ & $83 \pm 16$ & $\mathbf{0 . 0 1}$ \\
HDL (mg/dL) & $50 \pm 16$ & $44 \pm 11$ & $\mathbf{0 . 0 2}$ \\
LDL (mg/dL) & $102 \pm 35$ & $111 \pm 35$ & 0.2 \\
\hline & \multicolumn{1}{c}{ Median (Min.-Max.) } & 0.13 \\
Age (years) & $65(50-78)$ & $62(50-79)$ & 0.79 \\
Duration of T2DM (years) & $10(1-40)$ & $9.5(1-35)$ & $<\mathbf{0 . 0 0 1}$ \\
Edmonton score (points) & $9(7-13)$ & $4(1-6)$ & 0.06 \\
FPG (mg/dL) & $143(92-506)$ & $134(80-370)$ & $\mathbf{0 . 0 0 1}$ \\
Albumin (g/dL) & $4.3(3.4-4.7)$ & $4.4(2.9-4.9)$ & $\mathbf{0 . 0 4 5}$ \\
Triglyceride (mg/dL) & $124(36-588)$ & $159(59-408)$ & 0.93 \\
CRP (mg/L) & $3.8(0.1-18.5)$ & $3.6(0.1-49)$ & 0.37 \\
NLR (\%) & $1.98(0.5-4)$ & $2(0.8-4.8)$ & $\mathbf{0 . 0 2}$ \\
MPVLR (\%) & $3.9(1.4-13.2)$ & $3.4(1.5-6.9)$ & \\
\hline
\end{tabular}

Tab. 2. Accompanied conditions in frail and non-frail groups.

\begin{tabular}{|c|c|c|c|c|}
\hline & & Frail group & Non-frail group & $\mathrm{p}$ \\
\hline Diabetic neuropathy & $\begin{array}{l}\text { Present (n, \%) } \\
\text { Absent (n, \%) }\end{array}$ & $\begin{array}{l}12(29 \%) \\
30(71 \%)\end{array}$ & $\begin{array}{c}6(9 \%) \\
60(91 \%)\end{array}$ & 0.01 \\
\hline Diabetic retinopathy & $\begin{array}{l}\text { Present (n, \%) } \\
\text { Absent (n, \%) }\end{array}$ & $\begin{array}{l}14(33 \%) \\
28(67 \%)\end{array}$ & $\begin{array}{l}10(15 \%) \\
56(85 \%)\end{array}$ & 0.03 \\
\hline Cerebrovascular disease & $\begin{array}{l}\text { Present (n, \%) } \\
\text { Absent (n, \%) }\end{array}$ & $\begin{array}{c}3(7 \%) \\
39(93 \%)\end{array}$ & $\begin{array}{c}0(0 \%) \\
66(100 \%)\end{array}$ & 0.03 \\
\hline
\end{tabular}

( $p=0.13$ ). The frail group consisted of 27 women and 15 men while the non-frail group consisted of 30 women and 36 men (p $=0.06$ ). Age and gender of the frail and non-frail groups were not statistically different.

Blood urea $(p=0.20)$, creatinine $(p=0.96)$, FPG $(p=0.06)$, CRP $(p=0.93), \operatorname{HbA1c}(p=0.06)$, body weight $(p=0.25)$, waist circumference ( $p=0.68)$, BMI $(p=0.24)$ of the frail and non-frail groups were not statistically different. Total cholesterol $(p=0.28)$, LDL $(p=0.2)$, urea $(p=0.2)$, creatinine $(p=0.96)$ and diabetes duration ( $p=0.79$ ) of the frail and non-frail groups were also not statistically different. Hb $(p=0.04)$, GFR $(p=0.01)$, HDL ( $=$ $0.02)$, albumin $(p=0.001)$, and triglyceride $(p=0.045)$ levels of the frail and non-frail groups were statistically different. General characteristics and laboratory data of the frail and non-frail groups are summarized in Table 1.

The rates of well- and poorly controlled diabetics in frail and non-frail groups were not statistically different $(p=0.91)$. The number of diabetics with nephropathy was similar in frail and non-frail groups $(\mathrm{p}=0.11)$. The rates of coronary heart disease ( $\mathrm{p}$ $=0.8)$ and peripheral arterial disease $(\mathrm{p}=0.26)$ were also similar in study groups. Diabetic neuropathy $(\mathrm{p}=0.01)$, diabetic retinopathy $(p=0.03)$ and cerebrovascular diseases $(p=0.03)$ were more common in the frail group compared to non-frail group. Table 2 shows the rate of accompanied conditions in frail and -frail groups.

Although NLR of the frail (1.98 [0.54] \%) and non-frail (2 [0.8-4.8] \%) groups were not statistically different $(p=0.37)$, MPVLR of the frail group (3.9 [1.4-13.2] $\%)$ was significantly higher than that of the non-frail group (3.4 [1.5-6.9] \%; $p=0.02$ ).

In correlation analysis, MPVLR was found to be positively and significantly correlated with Edmonton Frail Score of the participants $(\mathrm{r}=0.21, \mathrm{p}=0.03)$.

The ROC analysis revealed that MPVLR levels greater than $3.41 \%$ have $71 \%$ sensitivity and $51 \%$ specifity in predicting frailty (AUC: 0.63 [95\% CI: 0.52-0.74]; p $=0.02$ ) (Fig. 1).

\section{Discussion}

Present study showed that MPVLR of frail type 2 diabetic subjects was significantly higher than the MPVLR of non-frail diabetic patients. In addition, MPVLR was significantly and positively correlated with Edmonton Frail Scale point of the participants and predicts frailty with high sensitivity and moderate specificity over the 3.41\% threshold.

Associations between inflammatory markers and frailty are being studied in recent works in literature. Elevated levels of interleukin-6 and CRP were suggested to 


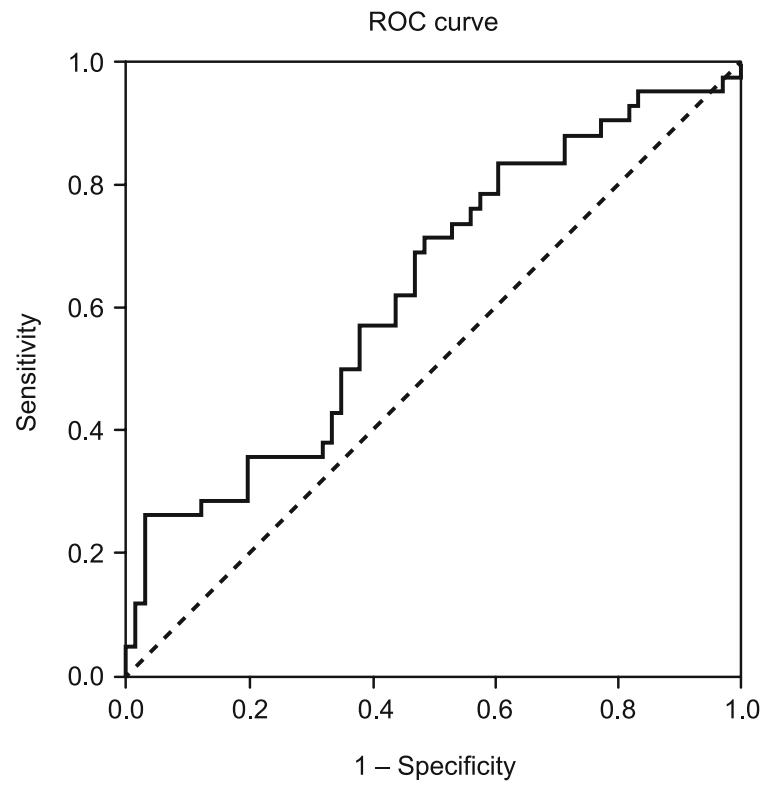

Fig. 1. ROC curve of MPVLR in predicting frailty.

be indicators of frailty in the elderly (13). Inflammation in older population, referred to as inflammageing, was suggested to be related with sarcopenia and frailty in humans $(13,14)$. Hemogram-derived inflammatory markers were also studied in frailty. Authors reported that NLR and red cell distribution width were weakly correlated with frailty in subjects with coronary heart disease (15). In another study, it was concluded that in patients with cancer, the NLR was correlated with Carolina Frailty index, another scale for determining frailty (16). However, NLR levels of the frail and non-frail diabetic subjects were not statistically different in the present report. Moreover, NLR did not correlate with the frailty score determined by Edmonton Frail Scale.

Studies in literature reported elevated MPVLR in various inflammatory diseases. High MPVLR was suggested to be helpful in the diagnosis of acute appendicitis (17). On the other hand, a decrease in MPVLR has been reported to be useful in predicting coronary artery lesions in Kawasaki disease (18). In 2016, Hudzik et al found that diabetic patients with increased MPVLR had worse angiographic features than those without increased MPVLR, while MPVLR could be an independent risk factor of mortality in those patients (8). MPVLR levels of type 2 diabetic subjects were studied while elevated MPVLR has been reported in subjects with diabetic nephropathy compared to those without diabetic nephropathy (7). Moreover, a significant and positive correlation between HbA1c and MPVLR has been confirmed (6). Interestingly, MPVLR was proposed as a predictor of poor outcome in subjects with ischemic stroke (19). Accordingly, in the present study, we reported elevated MPVLR levels in frail subjects as compared to non-frail diabetic patients, however, the correlation between MPVLR and HbA1c was not significant, possibly due to small study population. Since inflammatory markers are higher in frail subjects as compared to those without frailty, one can deduce that frailty is an inflammatory condition. Therefore, the results of our study are not in conflict with knowledge reported in literature.

We shall speculate about why MPVLR increases with frailty in diabetic patients. MPV and lymphocyte count, contributors of MPVLR, are associated with inflammatory conditions. Increased MPV levels have been reported in chronic prostatitis (20), liver steatosis $(21,22)$, diabetes mellitus (23), thyroiditis (24), rheumatoid arthritis (25-27), herniated lumbar disc pathologies (28), obesity (29), and inflammatory bowel disease (30). As the inflammatory burden accompanies frailty, MPV of the frail diabetic subjects in our report could be increased and thus be the factor contributing to the elevation of MPVLR. Moreover, a decrease in lymphocyte count was reported to occur during systemic inflammation (31, 32), which could also contribute to the elevation of MPVLR in present study.

A relatively small study cohort and retrospective design of the study are two important limitations of the present work. However, to the best of our knowledge, this is the first report on the association between MPVLR and frailty in type 2 diabetic subjects.

\section{Conclusion}

We suggest that elevated MPVLR could be a finding that marks frailty in diabetic subjects. Inexpensive and easy-to-assess nature of MPVLR may be useful in predicting frailty in type 2 diabetic population.

\section{Learning Points}

Evaluation of frailty in patients with T2DM by MPVLR is recommended since it is an easy-to-assess and inexpensive tool.

\section{References}

1. Zimmet PZ. Kelly West Lecture 1991. Challenges in diabetes epidemiology - from West to the rest. Diabetes care 1992; 15 (2): 232-252.

2. Holman RR, Paul SK, Bethel MA, Matthews DR, Neil HA. 10-year follow-up of intensive glucose control in type 2 diabetes. N Eng J Med 2008; 359 (15): 1577-1589.

3. Hayward RA, Reaven PD, Wiitala WL, Bahn GD, Reda DJ, Ge L et al. Follow-up of glycemic control and cardiovascular outcomes in type 2 diabetes. N Eng J Med 2015; 372 (23): 2197-2206.

4. Patel A, MacMahon S, Chalmers J, Neal B, Billot L, Woodward M et al. Intensive blood glucose control and vascular outcomes in patients with type 2 diabetes. N Eng J Med 2008; 358 (24): 2560-2572.

5. Duman TT, Aktas G, Atak BM, Kocak MZ, Erkus E, Savli H. Neutrophil to lymphocyte ratio as an indicative of diabetic control level in type 2 diabetes mellitus. Afr Health Sci 2019; 19 (1): 1602-1606.

6. Bilgin S, Aktas G, Kocak MZ, Atak BM, Kurtkulagi O, Duman TT et al. Association between novel inflammatory markers derived from hemogram indices and metabolic parameters in type 2 diabetic men. Aging Male 2019 Jun 28; 1-5. doi: 10.1080/13685538.2019.1632283

7. Kocak MZ, Aktas G, Erkus E, Duman TT, Atak BM, Savli H. Mean Platelet Volume to Lymphocyte Ratio as a Novel Marker for Diabetic Nephropathy. J Coll Physicians Surg Pak 2018; 28 (11): 844-847. 
8. Hudzik B, Szkodziński J, Lekston A, Gierlotka M, Poloński L, Gąsior M. Mean platelet volume-to-lymphocyte ratio: a novel marker of poor short- and long-term prognosis in patients with diabetes mellitus and acute myocardial infarction. J Diabetes Complications 2016; 30 (6): 1097-1102.

9. Bortz WM 2nd. The physics of frailty. J Am Geriatr Soc 1993; 41 (9): 1004-1008.

10. Lipsitz LA, Goldberger AL. Loss of 'complexity' and aging. Potential applications of fractals and chaos theory to senescence. JAMA 1992; 267 (13): 1806-1809.

11. Rolfson DB, Majumdar SR, Tsuyuki RT, Tahir A, Rockwood K. Validity and reliability of the Edmonton Frail Scale. Age ageing 2006; 35 (5): 526-529.

12. Bilgin S, Aktas G, Kurtkulagi O, Atak BM, Duman TT. Edmonton frail score is associated with diabetic control in elderly type 2 diabetic subjects. J Diabetes Metab Disord 2020; 19 (1): 511-514.

13. Soysal P, Stubbs B, Lucato P, Luchini C, Solmi M, Peluso R et al. Inflammation and frailty in the elderly: A systematic review and metaanalysis. Ageing Res Rev 2016; 31: 1-8.

14. Schaap LA, Pluijm SM, Deeg DJ, Harris TB, Kritchevsky SB, Newman AB et al. Higher inflammatory marker levels in older persons: associations with 5-year change in muscle mass and muscle strength. J Gerontol A Biol Sci Med Sci 2009; 64 (11): 1183-1189.

15. Hou P, Xue HP, Mao XE, Li YN, Wu LF, Liu YB. Inflammation markers are associated with frailty in elderly patients with coronary heart disease. Aging 2018; 10 (10): 2636-2645.

16. Nishijima TF, Deal AM, Williams GR, Guerard EJ, Nyrop KA, Muss HB. Frailty and inflammatory markers in older adults with cancer. Aging 2017; 9 (3): 650-664.

17. Bozlu G, Akar A, Durak F, Kuyucu N. Role of mean platelet volumeto-lymphocyte ratio in the diagnosis of childhood appendicitis. Arch Argent Pediatr 2019; 117 (6): 375-380.

18. Bozlu G, Karpuz D, Hallioglu O, Unal S, Kuyucu N. Relationship between mean platelet volume-to-lymphocyte ratio and coronary artery abnormalities in Kawasaki disease. Cardiol Young 2018; 28 (6): 832-836.

19. Chen SY, Lin YS, Cheng YF, Wang H, Niu XT, Zhang WL. Mean Platelet Volume-To-Lymphocyte Ratio Predicts Poor Functional Outcomes Among Ischemic Stroke Patients Treated With Intravenous Thrombolysis. Front Neurol 2019; 10; 10: 1274. doi: 10.3389/fneur.2019.01274.
20. Aktas G, Cakiroglu B, Sit M, Uyeturk U, Alcelik A, Savli H et al. Mean platelet volume: a simple indicator of chronic prostatitis. Acta Med Mediterr 2013; 29: 551-554.

21. Aktas G, Alcelik A, Tekce BK, Savlı H, Uyeturk U, Kurt M et al. Mean platelet volume and red cell distribution width in hepatosteatosis. Natl J Med Res 2013; 3 (3): 264-266.

22. Shin W-Y, Jung D-H, Shim J-Y, Lee H-R. The association between non-alcoholic hepatic steatosis and mean platelet volume in an obese Korean population. Platelets 2011; 22 (6): 442-446.

23. Cakir L, Aktas G, Enginyurt O, Cakir SA. Mean platelet volume increases in type 2 diabetes mellitus independent of HbA1c level. Acta Med Mediterr 2014; 30 (2): 425-428.

24. Sit M, Kargi E, Gulaliaktas, Dikbas O, Alcelik A, Savli H. Mean platelet volume should be a useful indicator in diagnosis of Hashimoto's thyroiditis. Acta Med Mediterr 2014; 30 (6): 1263-1266.

25. Kisacik B, Tufan A, Kalyoncu U, Karadag O, Akdogan A, Ozturk MA et al. Mean platelet volume (MPV) as an inflammatory marker in ankylosing spondylitis and rheumatoid arthritis. Joint Bone Spine 2008; 75 (3): 291-294.

26. Cakir L, Aktas G, Mercimek OB, Enginyurt O, Kaya Y, Mercimek $\mathbf{K}$. Are red cell distribution width and mean platelet volume associated with rheumatoid arthritis? Biomed Res 2016; 27 (2): 292-294.

27. Gasparyan AY, Stavropoulos-Kalinoglou A, Toms TE, Douglas KM, Kitas GD. Association of mean platelet volume with hypertension in rheumatoid arthritis. Inflamm Allergy Drug Targets 2010; 9 (1): 45-50.

28. Dagistan Y, Dagistan E, Gezici AR, Halicioglu S, Akar S, Özkan N et al. Could red cell distribution width and mean platelet volume be a predictor for lumbar disc hernias? Ideggyogy Sz 2016; 69 (11-12): 411-414.

29. Aktas G, Kocak MZ, Duman TT, Erkus E, Atak BM, Sit M et al. Mean Platelet Volume (MPV) as an inflammatory marker in type 2 diabetes mellitus and obesity. Bali Med J 2018; 7 (3): 650-653.

30. Kapsoritakis AN, Koukourakis MI, Sfiridaki A, Potamianos SP, Kosmadaki MG, Koutroubakis IE et al. Mean platelet volume: a useful marker of inflammatory bowel disease activity. The Am J Gastroenterol 2001; 96 (3): 776-781.

31. Zahorec R. Ratio of neutrophil to lymphocyte counts-rapid and simple parameter of systemic inflammation and stress in critically ill. Bratisl Lek Listy 2001; 102 (1): 5-14.

32. Gabay C, Kushner I. Acute-phase proteins and other systemic responses to inflammation. The N Eng J Med 1999; 340 (6): 448-454.

Received August 8, 2020. Accepted September 16, 2020. 